\title{
TerraSAR-X Instrument Operations Rooted in the System Engineering and Calibration Project
}

\author{
Ulrich Steinbrecher, Daniel Schulze, Johannes Böer, and Josef Mittermayer, Member, IEEE
}

\begin{abstract}
This paper presents the TerraSAR-X instrument operations embedded into the Instrument Operations and Calibration Segment. Special focus is on the data-take (DT) command generation. The command generation for standard DTs is discussed, and the nonnominal DT commanding is described for several examples which demonstrate the flexibility of both the TerraSAR-X instrument and the instrument operations system on-ground.
\end{abstract}

Index Terms-Synthetic aperture radar (SAR), TerraSAR-X instrument operations, TerraSAR-X System Engineering and Calibration (SEC) project.

\section{INTRODUCTION}

$\mathbf{T}$ HIS paper is subdivided into two parts. In the first part, an overview about the System Engineering and Calibration (SEC) project is provided, which shall support the reader of the special issue in understanding the tasks and responsibilities of SEC as a part of the TerraSAR-X ground segment [1], [2]. In the second part, SEC is presented as the provider of the TerraSAR-X instrument operations functionality. The SEC project has been conducted by the Microwaves and Radar Institute of DLR.

The task of instrument operations is to operate the synthetic aperture radar (SAR) instrument in its different operational SAR modes, namely, Stripmap, ScanSAR, and Spotlight, as well as experimental modes and to provide all required information about the instrument for satellite commanding and SAR data processing. The generation of data-take (DT) instrument commands is discussed for both, standard DTs in the nominal modes and beams of TerraSAR-X (TSX) as well as for experimental DTs.

The flexibility of the TSX instrument is demonstrated by image results from several experimental DTs.

\section{SEC SEGMENT}

SEC is one of the three projects which have constructed the TerraSAR-X ground system [2], [18]. The SEC project is in charge of the SAR system engineering and the building of the system Instrument Operations and Calibration Segment (IOCS).

Manuscript received February 28, 2009; revised June 21, 2009. First published December 4, 2009; current version published January 20, 2010.

The authors are with the German Aerospace Center (DLR), 82230 Wessling, Germany (e-mail: ulrich.steinbrecher@dlr.de; Daniel.Schulze@ dlr.de; Johannes.Boeer@dlr.de; josef.mittermayer@dlr.de).

Color versions of one or more of the figures in this paper are available online at http://ieeexplore.ieee.org.

Digital Object Identifier 10.1109/TGRS.2009.2032177
Fig. 1 shows an overview of SEC and shows on the left side the three sections of IOCS, i.e., instrument operations, calibration, and verification. On the right, the figure shows the main tasks of SAR system engineering, namely, instrument shadow engineering (assistance at SAR instrument developer site during instrument development and test), SAR system performance, and system engineering support.

The other two segments of the TerraSAR-X ground system are Mission Operations (MOS) and Payload Ground Segment (PGS), which are in charge of the total satellite bus control and the SAR data processing, respectively. In the MOS segment, there are embedded IOCS subsystems for instrument health monitoring and for the conversion of DT requests into SAR instrument commands [19].

The most prominent tasks of the Calibration section [5], [6] are internal and external calibration. The internal calibration provides measurements on instrument errors during and outside data taking and thus allows for the correction of these errors in the SAR processing. The external calibration adjusts and measures the absolute radiometric performance of the SAR system by means of calibration reference targets.

Based on inputs from the SAR system engineering, the antenna patterns of TSX are optimized to fulfill requirements established by the overall SAR system performance, i.e., the excitation of the individual transmit/receive modules (TRMs) of TSX is calculated. The antenna pattern determination on the other side is based on measurements from the external calibration and an antenna model and provides the operational antenna patterns to the SAR processing.

The Verification Section ensures the correct in-orbit operation of the entire SAR system from DT instrument command generation to ground processing. Within this section, the SAR system verification was performed during the commissioning phase [7]. This activity is continued to maintain the SAR instrument performance during the whole mission. The main subsystems are characterization/verification/monitoring tools, DT verification, long-term SAR system monitoring, and instrument health monitoring.

In the frame of SAR system engineering, the SEC project supports the ground segment and the overall TSX project management with SAR system know-how. Important responsibilities are as follows:

1) specification of TerraSAR-X modes and imaging beams;

2) overall SAR system performance control;

3) instrument shadow engineering;

4) attendance at instrument acceptance tests;

5) technical support for project management decisions;

6) algorithm development for spotlight SAR processing; 


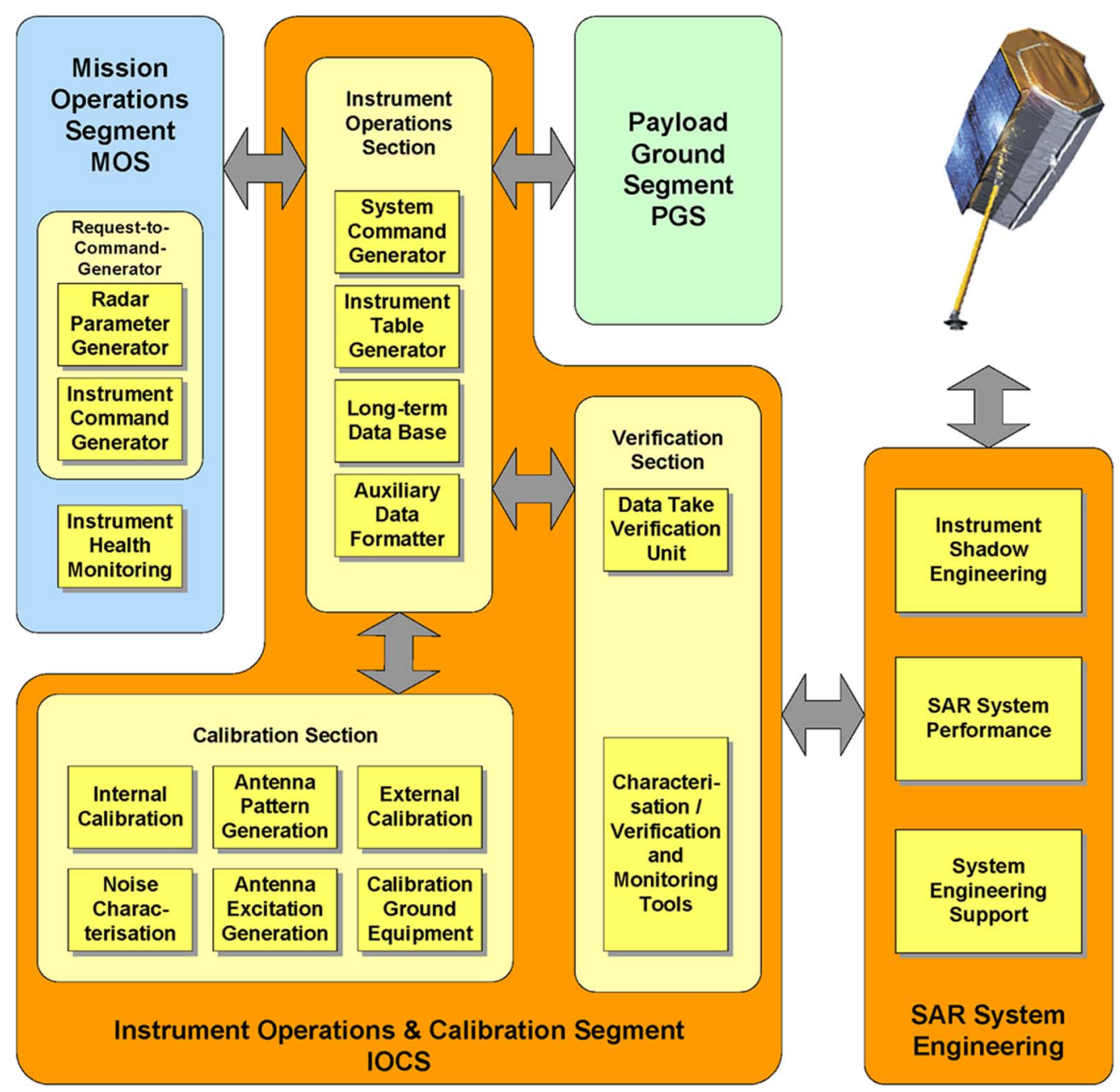

Fig. 1. Overview about System Engineering and Calibration segment.

7) definition of attitude law for Doppler centroid minimization.

\section{INSTRUMENT OPERATIONS SECTION}

\section{A. Instrument Operations Tasks and Architecture}

The main tasks of the instrument operations section can be summarized as follows.

1) Generate, maintain, archive, and distribute all required instrument tables for use onboard and on-ground.

2) Generation of radar parameters and command information for each SAR data acquisition.

3) Development of flight procedures w.r.t. the SAR instrument for nominal and contingency operations.

4) Provision and maintenance of the Long-Term Data Base (LTDB) for archiving all relevant instrument information during the whole mission.

5) Provision of the Auxiliary Product, which contains all required calibration and instrument information for the SAR data processing.

In order to fulfill these tasks, the architecture of instrument operations is based on a huge data archive in the central position, i.e., the LTDB surrounded by peripheral subsystems (see Fig. 2).

\section{B. $L T D B$}

One major task of the LTDB is to provide a whole mission history of all required data for system performance prediction and execution of corrective measures. The data archived for that purpose are as follows:

1) instrument telemetry and performance data;

2) orbit and attitude data;

3) calibration data;

4) SAR processor settings;

5) SAR product quality reports.

Thus, within the LTDB, all mission data relevant for SAR system performance are brought together and can be relationally accessed by calibration, characterization, monitoring, and verification tools.

This shortens the response time for contingency analysis and countermeasures and enables a deeper understanding of the interaction between instrument hardware and SAR performance. The Long-Term System Monitoring is able to better 


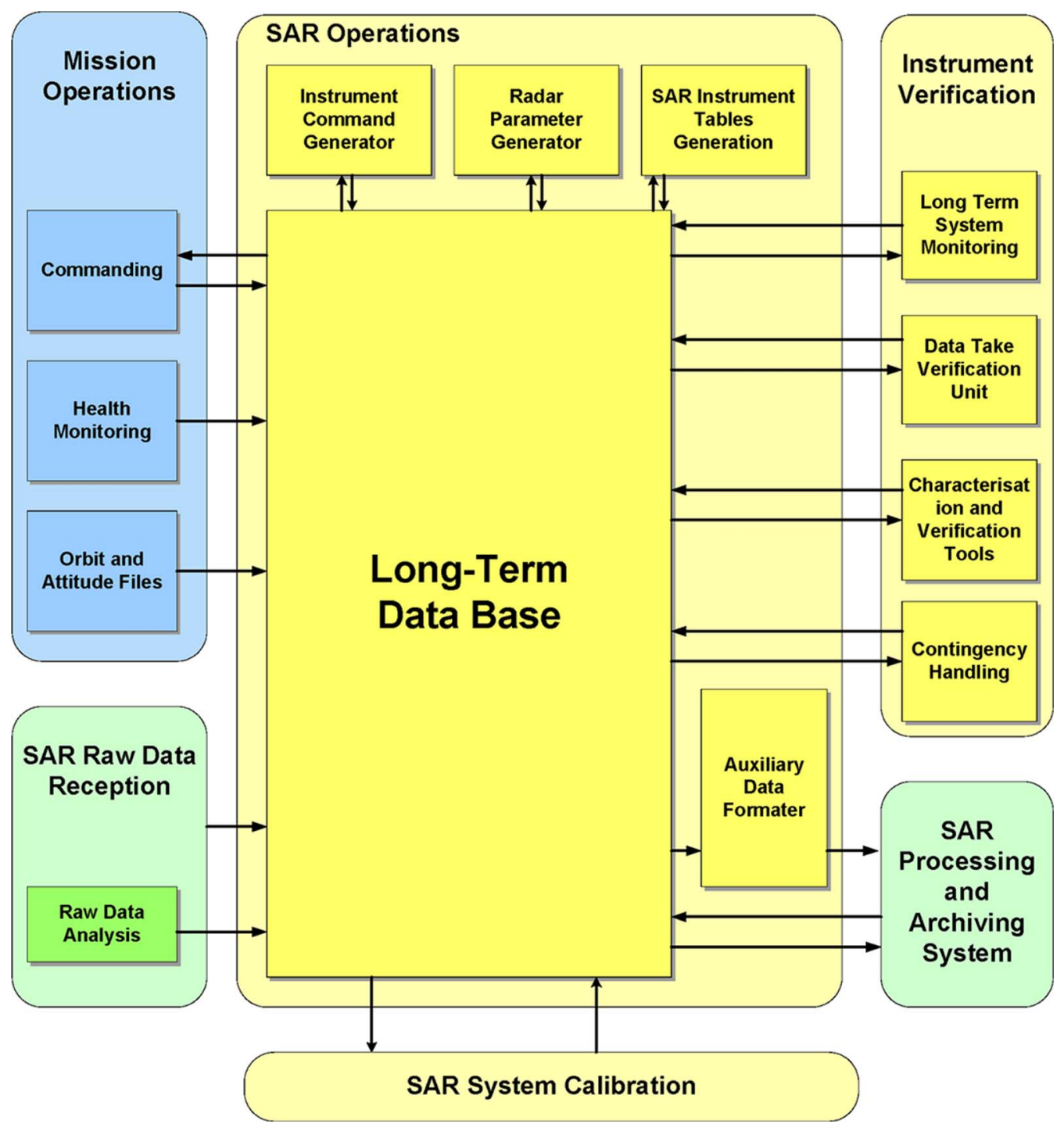

Fig. 2. Position of Long-Term Data Base within the Instrument Operations and Calibration Segment.

detect performance degradations with more anticipation and thus enhances the instrument degradation mitigation.

\section{SAR Instrument Tables}

The instrument configuration is controlled via onboard instrument tables for total zero Doppler steering [8] attitude law, the pulse-repetition-frequency (PRF) values for data taking, custom Tx pulse waveforms, gain settings, and the antenna excitation coefficients. The onboard instrument tables are also provided on-ground to the SAR DT command generation and SAR processing.

\section{Nominal DT Command Generation Flow}

Fig. 3 shows, on the left-hand side, the elementary steps in the DT command generation for nominal TSX basic products. Via the EOWEB interface [9], the user is selecting the SAR mode and the region to be imaged. This information is ingested in the form of a SAR acquisition request into the Radar Parameter Generator (RPG) and Instrument Command Generator (ICG) subsystems. As can be seen in Fig. 1, these

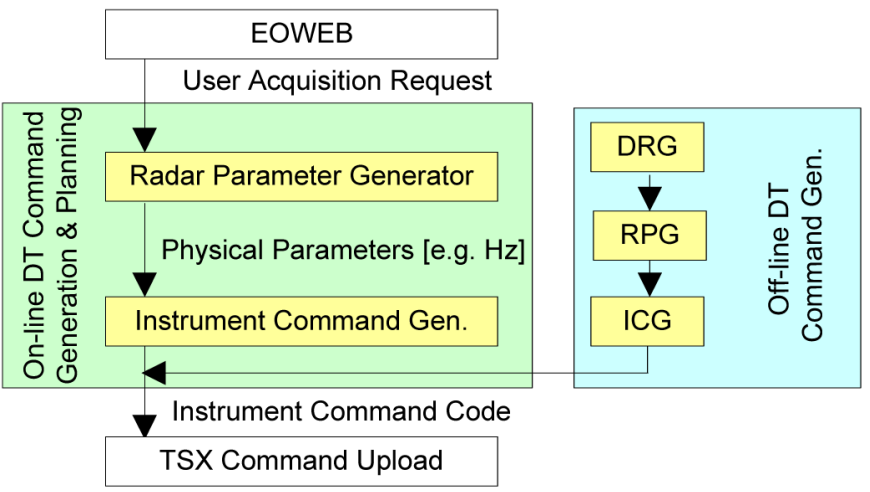

Fig. 3. TerraSAR-X online/offline DT instrument command generation. The left-hand side shows the elementary steps in the DT command generation for nominal TSX basic products. The right-hand side shows the elementary steps in the offline commanding for nonnominal DTs, i.e., system DTs in TSX nomenclature.

two IOCS subsystems are integrated into the MOS environment and are running automatically, i.e., online, for the generation of nominal TSX acquisitions as specified in the basic product specification [10]. 


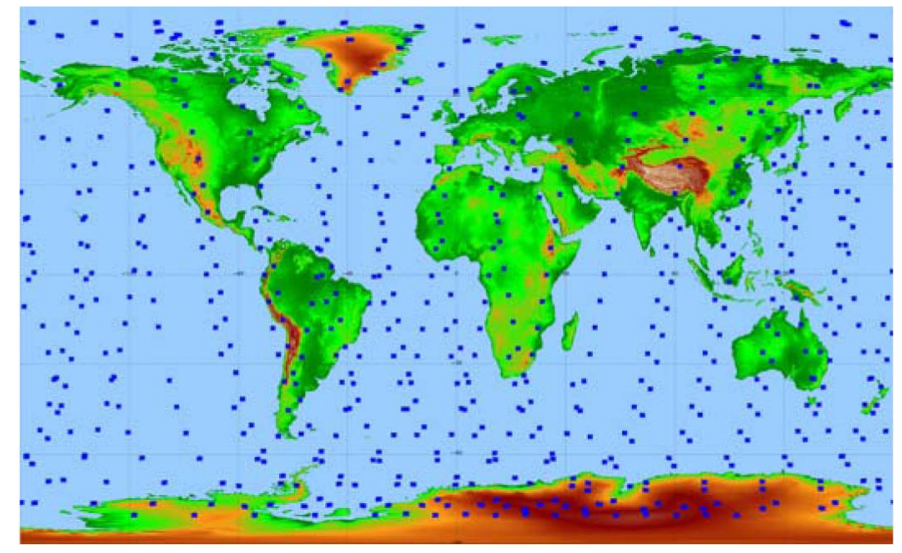

Fig. 4. Ground position of acquisitions during heat-up sequence.

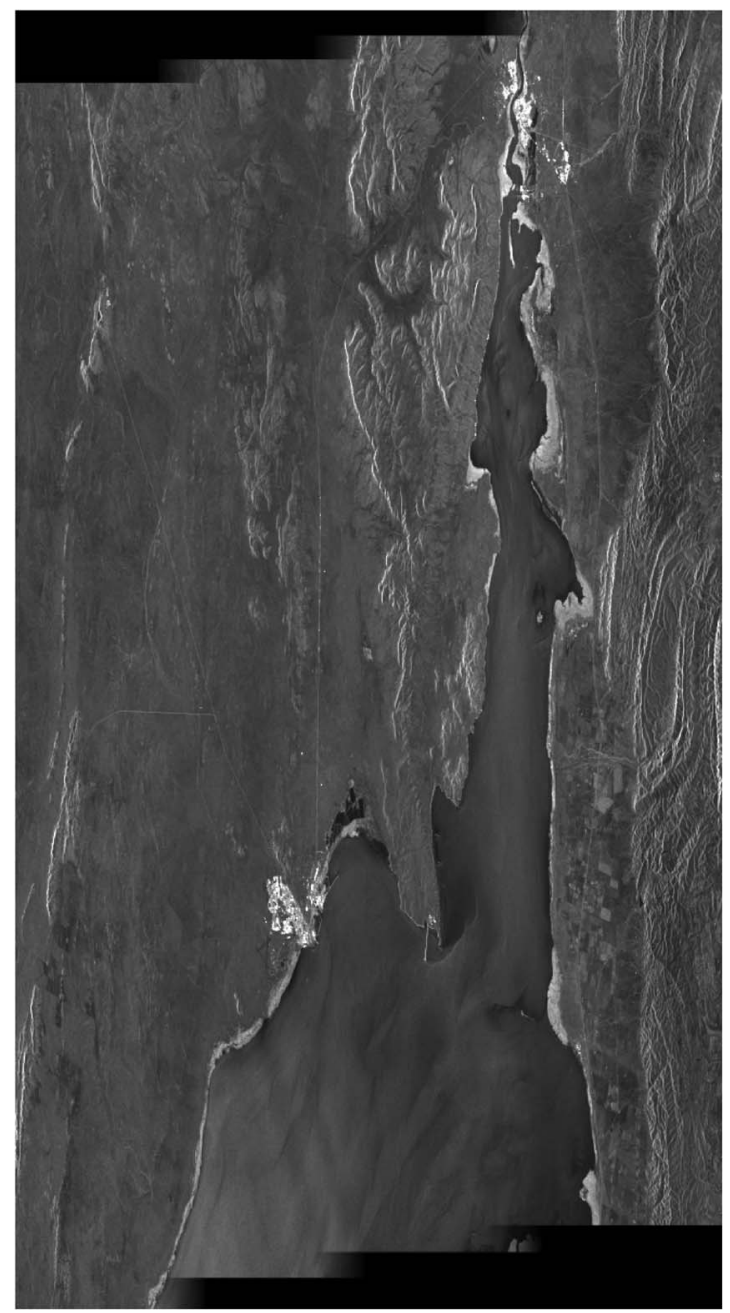

Fig. 5. TOPSAR acquisition in February 2009 in South Australia; the scene extension in range (horizontal) is about $100 \mathrm{~km}$. The scene dimension and resolution $(16 \mathrm{~m})$ is as in TerraSAR-X ScanSAR products.

From the user request, the RPG calculates the required instrument parameter settings for the DT acquisition in physical units, e.g., the PRF values, the gain settings, the antenna steering angles, or the SAR raw data compression ratio. The physical instrument parameter values are then coded by the ICG. The ICG converts the physical parameter values into indexes and

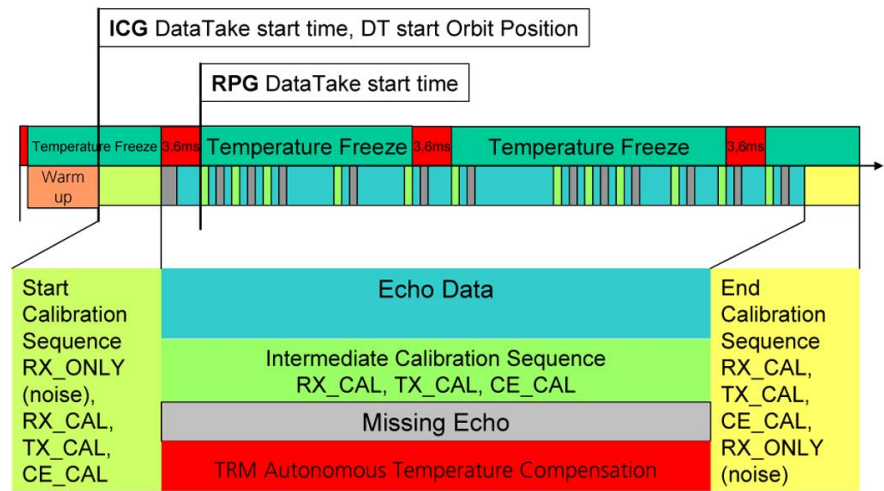

Fig. 6. Example of a possible TerraSAR-X DT structure. The echo data designated for the image generation are recorded after the "RPG Data Take start time" in the figure. Before and after these echo data, additional calibration measurements, as well as warm-up sequences, are executed.

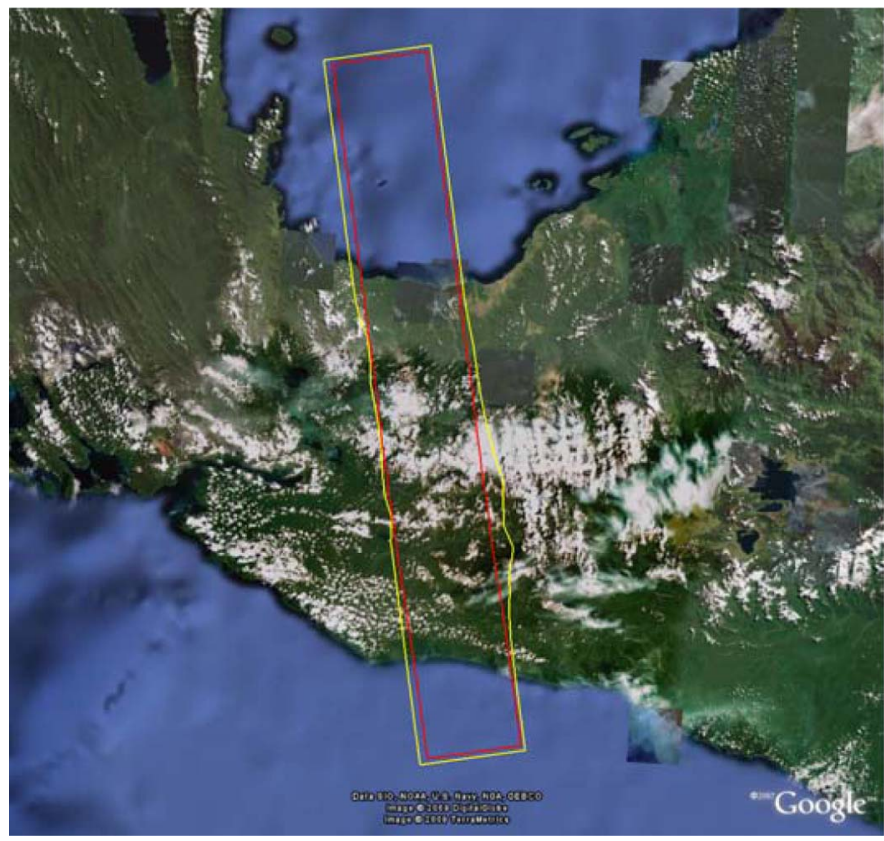

Fig. 7. Scene coverage verification after DT acquisition. The red polygon indicates the desired area, whereas the yellow polygon shows the acquired scene.

numbers to be commanded to the instrument. In this process, one major task is to attach internal calibration sequences to the commands. In the end, the ICG provides the instrument command code to the TSX command upload by MOS.

\section{E. DT Structure}

The whole process of instrument command code generation is rather complex. However, as an example, Fig. 6 shows a possible structure of a DT as it is coded in the output of the ICG.

The DT is initiated by an instrument warm-up sequence, followed by a calibration sequence. During the DT example in the figure, intermediate calibration is also carried out. In addition, specific changes in the instrument configuration may be inserted into the DT. In the figure, such a specific change would be to switch from "TRM autonomous temperature 


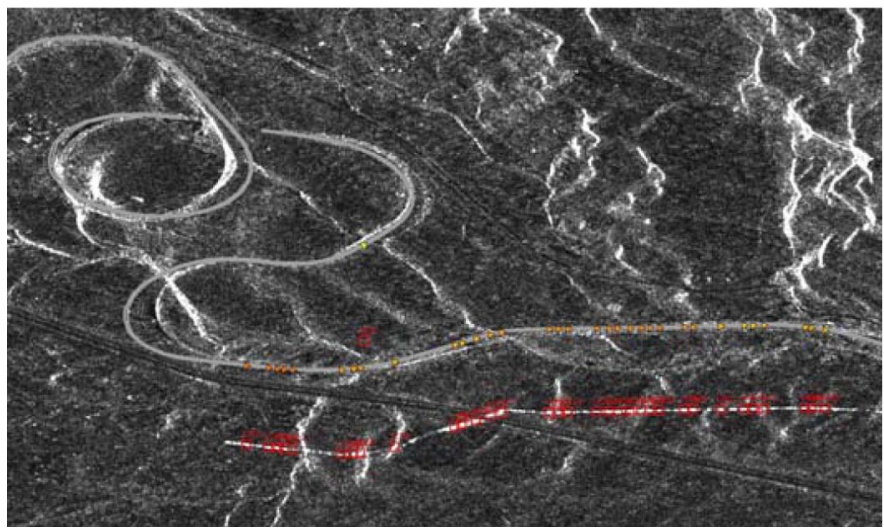

Fig. 8. Speed estimate of a train close by the Tehachapi rail loop utilizing the aperture switching technique.

compensation" to "temperature freeze" without autonomous temperature compensation.

\section{F. DT Command Verification}

In order to ensure the correct commanding of the TerraSAR-X SAR instrument, two DT commanding verification steps are implemented. First, before commanding inside the ICG, the final instrument command code is checked for nonallowed parameter combinations which harm the instrument or could result in a nonsuccessful data taking. For example, the maximum transmit duty cycle during a DT is checked to prevent thermal problems. Of course, the instrument is self-protecting by failure detection indication and recovery. However, the instrument command generation needs to be error free to optimize instrument throughput and performance.

The second DT commanding verification step is carried out after the acquisition by analysis of the acquired raw data in the DT verification unit (DTVU). The main input to the DTVU is a quality check product which is generated after SAR raw data reception by PGS. The sequence of instrument parameter settings during the DT execution is compared in the DTVU with the expected ones derived from the instrument command code. Another check is the correctness of the acquired scene location with the user-requested location, which depends not only on precise instrument switch-on and switch-off but also on the correct commanding of the radar echo window. As an example, Fig. 7 shows a control plot for an acquisition in Stripmap mode taken in January 2009 over Indonesia. The inner polygon (red) indicates the scene ordered by a user request, whereas the outer polygon (yellow) shows the boundaries of the recorded and processed scene.

After almost two years of successful TSX operation, the DTVU proved an almost error-free DT command generation.

\section{COMmanding of Experimental DTs}

This section shows how the instrument operations section is capable to fully address the flexibility of the TerraSAR-X instrument. The particular commanding of several exemplary experimental DTs is discussed, and acquired images are presented.

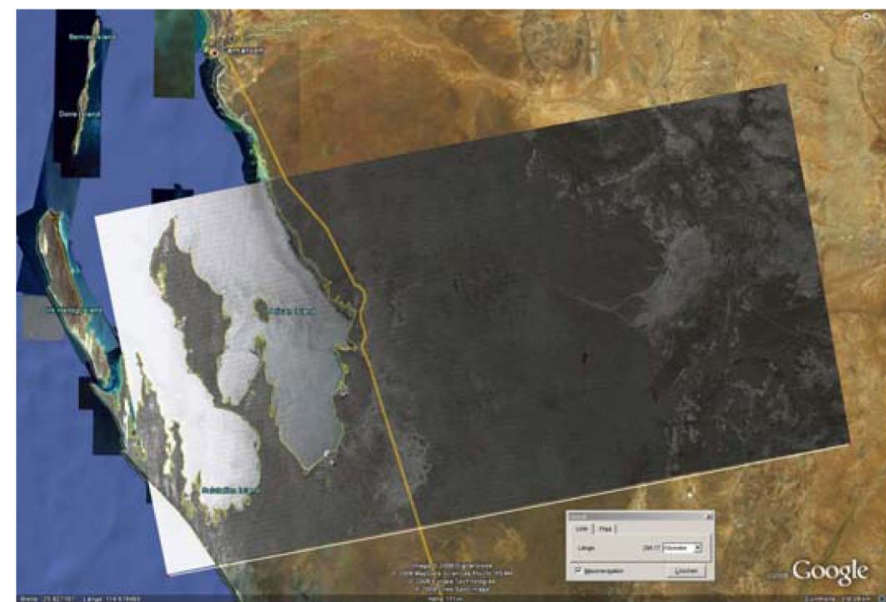

Fig. 9. Ultrawide (290-km ground range extension) six-beam ScanSAR acquired over West Australia with 30-m resolution and 150-km azimuth scene extension.

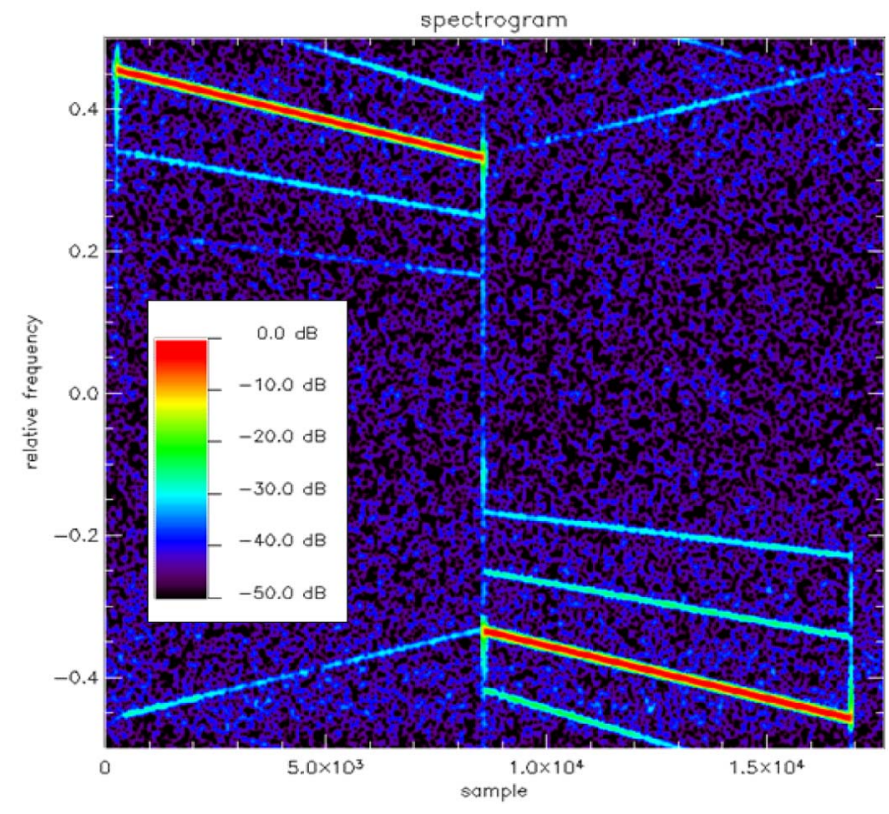

Fig. 10. Spectrogram of a split-bandwidth transmit pulse used for delta- $k$ interferometry.

\section{A. Experimental DT Command Generation Flow}

The System Command Generator (SCG) is the subsystem within IOCS, which provides the functionality for experimental DT command generation. It consists mainly of an offline DT request generator (DRG), which can produce an experimental user acquisition request for a desired scene location and mode. In addition, several standard and experimental versions of the RPG and the ICG can be accessed inside the SCG.

Fig. 3 shows, on the right-hand side, the principal flow of the experimental DT instrument command generation. The basic principle is to use the online RPG and ICG subsystems, but to allow expert user modification in the subsystem source code and in the intermediate command results, i.e., editing in the user acquisition request, the physical radar parameters, and the ICG output. 


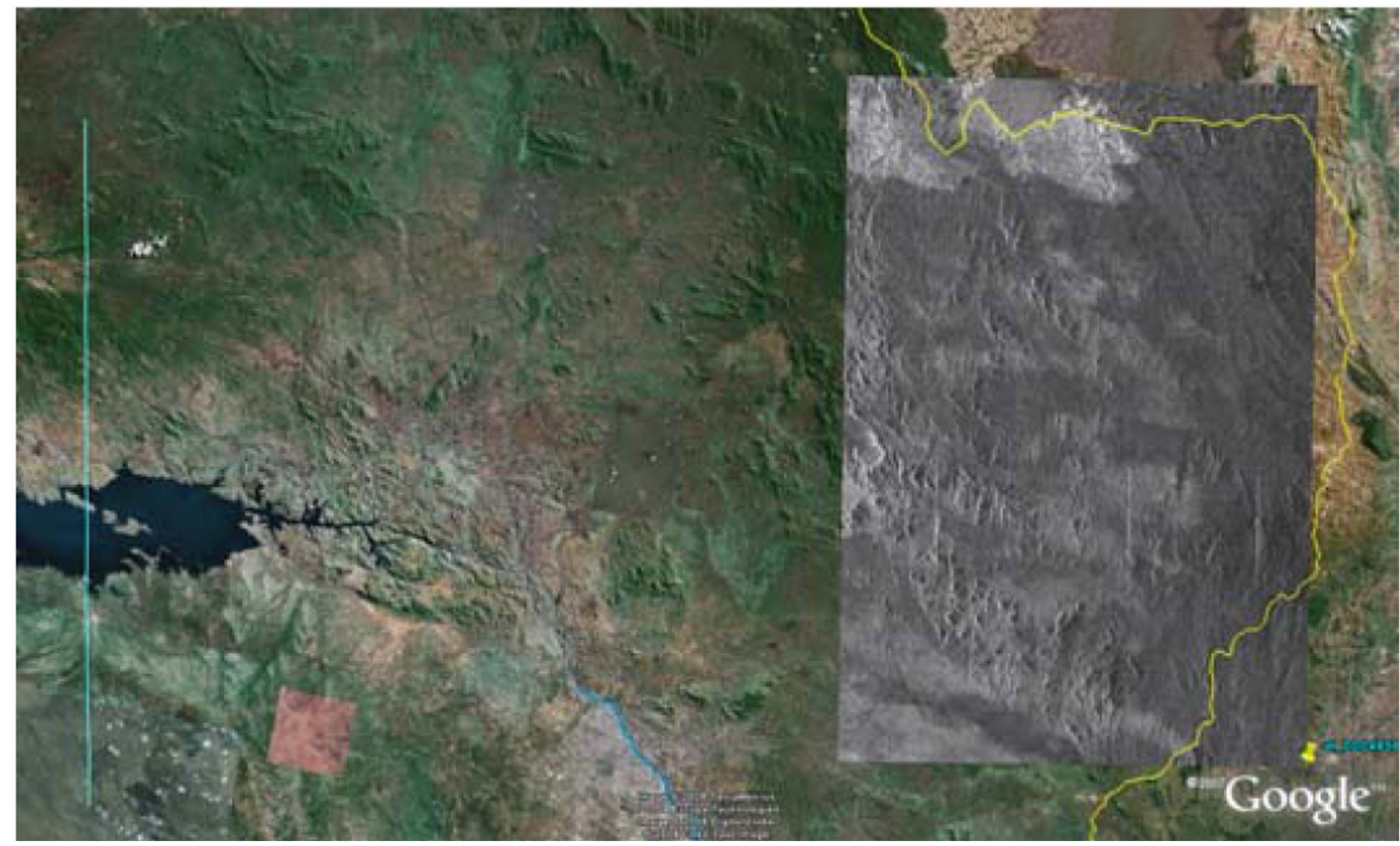

Fig. 11. Nadir echo demonstration DT with provoked nadir echoes in several ScanSAR subswaths. The turquoise line is the subsatellite track, from where the nadir echoes originate. See Fig. 12 for a zoom into the SAR image.

\section{B. Particular Commissioning-Phase DTs}

During commissioning phase, the extensive characterization and verification program [7], [17] required for numerous particular DTs realized as system orders, which differ from the standard TerraSAR-X products (basic orders). Examples are DTs for heating up the instrument, allowing for high-temperature characterization. Another group of DTs is particular due to their high number and worldwide distribution. Here, the specialty lies in the automatic DT request generation following a certain distribution. This pile of DTs supported SAR performance statistical analysis and overall system load tests [7], [17].

High-temperature instrument characterization DTs were generated with a reduced onboard memory consumption to put the emphasis on a high instrument operation time, i.e., DTs with 8-s duration were executed, whereas the recording of the echoes was only enabled for the first and the last $2 \mathrm{~s}$. This reduced the amount of data by a factor of two. In addition, the highest onboard data compression (BAQ $8: 2$ ) was commanded. The reduced demand on memory and data rate allowed for the acquisition of 40 DTs per orbit. This led to an instrument operation time of $320 \mathrm{~s}$ per orbit as required for heating up the instrument and thus for the instrument characterization in hot case [17].

Fig. 4 shows the global distribution of the DTs executed during the $44 \mathrm{~h}$ of heat-up sequence.

\section{DRA and Aperture Switching Mode}

For along-track interferometric applications, two SAR images with a baseline in along-track are required. TerraSAR-X is equipped with a special dual-receive-antenna (DRA) mode

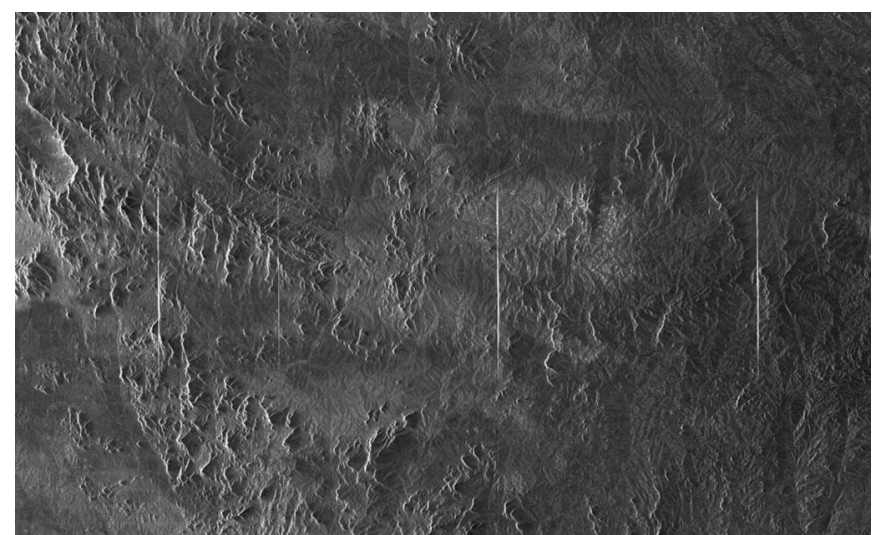

Fig. 12. Zoom into the SAR image of colored Fig. 11. Detail with nadir echoes.

[12], [20]. This DRA mode needs to operate the redundant receiving chain of the instrument and is therefore not always available.

In the run-up to the DRA mode and in order to allow for permanent along-track interferometry availability, an alternative mode has been developed, i.e., the aperture switching mode. It exploits the high-PRF available onboard TerraSAR-X for the generation of two virtual channels. A pulse-to-pulse alternating attenuation of the fore and after half of the antenna in receive is commanded, which builds up the two virtual channels for quasi-simultaneous acquisition of two SAR images with antenna phase centers separated in along-track.

Details on the interferometric processing results obtained from acquisitions in the aperture switching mode are discussed 
in [13] and [14]. Fig. 8 shows a velocity measurement example obtained from an aperture switching acquisition where the movement was detected by the phase difference in the fore and aft channel. The displacement of the moving object (train) in the SAR image can clearly be observed. From the amount of dislocation, the velocity of the moving object can be calculated. The orange dots on top of the gray railroad indicate the true position of the moving targets. The red squares identify the corresponding positions as found in the SAR image.

\section{TOPSAR Mode}

The TSX SAR instrument has the ability to repeat sequences of elevation and/or azimuth beams. In principle, the proper selection of beams and sequences of beams results in Stripmap, ScanSAR, or Spotlight acquisitions.

The terrain observation by progressive scan synthetic aperture radar (TOPSAR) mode overcomes the limitations imposed by the ScanSAR mode by steering the antenna along-track during the acquisition of a burst while maintaining the same performance in resolution and swath width as in ScanSAR. The results of the TOPSAR acquisitions with TerraSAR-X are described in detail in [3] and [4].

The azimuth resolution enhancement in spotlight acquisitions is obtained by the steering of the antenna against the flight direction, which prolongs the illumination time of a target on the ground. In TOPSAR, the antenna is steered in the flight direction, causing a shorter illumination of the targets but an increase of the illuminated scene in azimuth.

The commanding of a TOPSAR acquisition in TerraSAR is achieved by combining commanding modules from ScanSAR and Spotlight. The ScanSAR command sequence forms the frame of subswaths. Inside each subswath command block, a sequence of azimuth pattern steering is embedded in a reverse order to the TerraSAR-X spotlight modes. Fig. 5 shows a TOPSAR image acquired in South Australia.

The advantage of a TOPSAR DT compared to a ScanSAR DT is its homogenous performance of signal-to-noise ratio (SNR) and azimuth ambiguity ratio along azimuth and the absence of scalloping (see [3] for details).

\section{E. Wide-Beam ScanSAR}

The operation concept of programming a DT instead of using predefined settings gives the ability to select more than the nominal four beams for a TerraSAR-X ScanSAR DT. For acquisition geometry with steep incidence angles, the slantto ground-range projection comprises the potential to cover a wide subswath with a moderate echo window length. Special elevation beams were created which support the area recorded by the long echo window.

Fig. 9 shows a six-wide-beam ScanSAR acquisition over Australia. The SAR image is about $290 \mathrm{~km}$ wide (ground range) and $150 \mathrm{~km}$ long (azimuth). The SAR image in the figure shows only a small part of the overall acquired DT with the dimensions of $290-\mathrm{km}$ ground range $\times 840-\mathrm{km}$ azimuth. The image has a resolution of about $30 \mathrm{~m}$ in azimuth. The range resolution is transformed in the same order by means of multilooking. The image was processed within the nominal processing chain for TerraSAR-X [16].

\section{F. Wide-Band (delta- $k$ ) Interferometry}

A basic problem for digital elevation model generation derived from cross-track interferometric data is the ambiguity in the height estimates. State-of-the-art phase unwrapper can retrieve the absolute height for most terrain types. In addition, multiple-baseline interferometry can help in the determination of the absolute height in a difficult terrain. Nevertheless, a stable absolute height estimator with just one interferometric image pair (single-pass acquisition) is desirable.

Instead of an additional baseline, a different RF carrier frequency can be used to support the resolving of the height of ambiguity. A system like TSX with range bandwidths of $300 \mathrm{MHz}$ can support the multiple RF carrier approach with just one carrier frequency by exploiting the high bandwidth.

Interferometric processing of an upper and a lower part of the bandwidth results in an absolute height estimate. Since only parts (upper and lower) of the transmitted pulse are used, the SNR decreases. TSX is capable of transmitting any custom waveforms, which is sampled and uploaded to the spacecraft. Special waveforms that are advantageous for the delta- $k$ interferometry approach are split bandwidth waveforms. These kinds of waveforms transmit only the part of the bandwidth required by the delta- $k$ interferometer.

Fig. 10 shows a time-frequency diagram of a split bandwidth transmit pulse. During the first half of the pulse duration, a down chirp in the upper left part of the diagram is visible at $0-\mathrm{dB}$ signal level. In the middle of the transmit pulse, the frequency jumps instantaneously to the other edge of the spectrum (lower right part) and continues with a down chirp until the lower edge of the maximum TerraSAR-X bandwidth is reached. There is no idle energy transmitted which would lead to a decrease in SNR (for further details and results see [15]).

\section{G. Nadir DT}

In the characterization of TerraSAR-X nadir echoes [11], special DTs were programmed and commanded, in which the echo window is intentionally open at the return time of the nadir reflection. Fig. 11 shows a Google Earth overlay with a gray TerraSAR-X four-beam ScanSAR image. The turquoise line on the left is the subsatellite track, source of the nadir echoes. It is interesting to observe in the image that normal terrain scatters only a low portion of the incident signal back to the satellite. Only the part where the subsatellite track crosses the water a direct nadir reflection is visible in the SAR image. Note the thin vertical lines in the zoom into the SAR image shown in Fig. 12.

\section{CONCLUSION}

In this paper, the SEC project within the TerraSAR-X ground segment has been presented. The IOCS system was summarized as the main contribution of SEC to the ground segment. The flow in the generation of the instrument command code for nominal and experimental DTs was presented. The instrument 
flexibility of TSX was demonstrated by several examples for experimental DTs.

In the process of building up the TerraSAR-X ground segment, it turned out that the combination of SAR system engineering and the development of the IOCS system, which integrates instrument operations together with SAR system calibration and verification, was a logic and very successful approach.

The high flexibility of the TerraSAR-X instrument allows for a huge number of different SAR products and applications. As a consequence, the SAR instrument operations is a rather challenging business since the flexibility of the instrument shall be kept to a maximum and a high reliability of the instrument operations needs to be ensured. The approach to define basic SAR products operated in a highly automated manner and the possibility of experimental DTs provided by an offline instrument command generation system within IOCS proved to be adequate to meet this challenge. The concept of an LTDB supports fast provision of all relevant instrument data for calibration, characterization, monitoring, verification, and contingency analysis purposes.

\section{ACKNOWLEDGMENT}

The authors would like to thank the following people for the provision of the images representing the result of the flexible TSX commanding. The processed Tehachapi Rail Loop image was provided by H. Runge and S. Suchandt. The TOPSAR image was commanded by S. Wollstadt and processed by P. Prats and N. Tous-Ramón. All other SAR images were processed using the operational TerraSAR-X multimode SAR processor. The authors would also like to thank H. Breit, T. Fritz, B. Schättler, and their team.

\section{REFERENCES}

[1] R. Werninghaus, "The TerraSAR-X mission and system design," IEEE Trans. Geosci. Remote Sens., vol. 48, no. 2, pp. 606-614, Feb. 2010.

[2] S. Buckreuß, "The TerraSAR-X ground segment," IEEE Trans. Geosci. Remote Sens., vol. 48, no. 2, pp. 623-632, Feb. 2010.

[3] A. Meta, J. Mittermayer, P. Prats, R. Scheiber, and U. Steinbrecher, "TOPS imaging with TerraSAR-X: Mode design and performance analysis," IEEE Trans. Geosci. Remote Sens., vol. 48, no. 2, pp. 759-769, Feb. 2010

[4] P. Prats, R. Scheiber, J. Mittermayer, A. Meta, and A. Moreira, "Processing of sliding spotlight and TOPS SAR data using baseband azimuth scaling," IEEE Trans. Geosci. Remote Sens., vol. 48, no. 2, pp. 770-780, Feb. 2010.

[5] M. Schwerdt, B. Bräutigam, M. Bachmann, B. Döring, D. Schrank, and J. Hueso Gonzalez, "Terrasar-X calibration results," in Proc. IGARSS, Boston, MA, 2008, pp. II-205-II-208.

[6] B. Bräutigam, J. Hueso Gonzalez, M. Schwerdt, and M. Bachmann, "TerraSAR-X instrument calibration results and extension for TanDEM-X," IEEE Trans. Geosci. Remote Sens., vol. 48, no. 2, pp. 702-715, Feb. 2010.

[7] J. Mittermayer, B. Schättler, and M. Younis, "TerraSAR-X commissioning phase execution summary," IEEE Trans. Geosci. Remote Sens., vol. 48, no. 2, pp. 649-659, Feb. 2010

[8] H. Fiedler, E. Boerner, J. Mittermayer, and G. Krieger, "Total zero Doppler steering-A new method for minimizing the Doppler centroid," IEEE Geosci. Remote Sens. Lett., vol. 2, no. 2, pp. 141-145, Apr. 2005.

[9] B. Schättler, H. Breit, T. Fritz, M. Eineder, E. Schwarz, H. Damerow, U. Blass, E. Boerner, and W. Balzer, "The TerraSAR-X payload ground segment: Pre-launch status and performance," in Proc. CEOS SAR Calibration Workshop, Edinburgh, U.K., 2006.

[10] M. Eineder, T. Fritz, J. Mittermayer, A. Roth, E. Börner, and H. Breit, TX-GS-DD-3302 TerraSAR-X Basic Product Specification,
DLR, Cologne, Germany, 2009. [Online]. Available: http://www.dlr. de/Portaldata/1/Resources/raumfahrt/weltraum/TX-GS-DD-3302_BasicProduct-Specification-Document_1.6.pdf

[11] S. Wollstadt and J. Mittermayer, "Nadir margins in TerraSAR-X, timing commanding," in Proc. CEOS, 2008.

[12] J. Mittermayer and H. Runge, "Conceptual studies for exploiting the TerraSAR-X dual receive antenna," in Proc. IGARSS, Toulouse, France, 2003, pp. 2140-2142

[13] S. Suchandt, H. Runge, H. Breit, A. Kotenkov, D. Weihing, and S. Hinz, "Traffic measurement with TerraSAR-X: Processing system overview and first results," presented at the European Conf. Synhetic Aperture Radar, Friedrichshafen, Germany, vol. 4, 2008, Paper 8.3.3.

[14] S. Suchandt, H. Runge, H. Breit, U. Steinbrecher, A. Kotenkov, and U. Balss, "Automatic extraction of traffic flows using TerraSAR-X alongtrack interferometry," IEEE Trans. Geosci. Remote Sens., vol. 48, no. 2, pp. 807-819, Feb. 2010.

[15] R. Brcic, M. Eineder, and R. Bamler, "Interferometric absolute phase determination with TerraSAR-X wideband SAR data," presented at the RadarCon, Pasadena, CA, 2009, Paper 3288.

[16] H. Breit, T. Fritz, U. Balss, A. Niedermeier, M. Lachaise, and M. Vonavka, "TerraSAR-X SAR processing and products," IEEE Trans. Geosci. Remote Sens., vol. 48, no. 2, pp. 727-740, Feb. 2010.

[17] J. Mittermayer, M. Younis, R. Metzig, S. Wollstadt, J. Márquez, and A. Meta, "TerraSAR-X system performance characterization and verification," IEEE Trans. Geosci. Remote Sens., vol. 48, no. 2, pp. 660676, Feb. 2010.

[18] R. Werninghaus, W. Balzer, S. Buckreuss, J. Mittermayer, and P. Mühlbauer, "The TerraSAR-X mission," in Proc. EUSAR, Ulm, Germany, 2004.

[19] E. Maurer, "TerraSAR-X mission planning system: Autonomous command generation for spacecraft operations," IEEE Trans. Geosci. Remote Sens., vol. 48, no. 2, pp. 642-648, Feb. 2010.

[20] M. Gabele, B. Bräutigam, D. Schulze, U. Steinbrecher, N. Tous-Ramon, and M. Younis, "Fore and aft channel reconstruction in the TerraSAR-X dual receive antenna mode," IEEE Trans. Geosci. Remote Sens., vol. 48, no. 2, pp. 795-806, Feb. 2010.

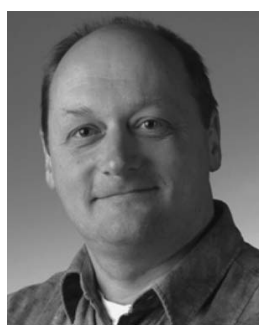

Ulrich Steinbrecher received the Dipl.-Ing. degree in electrical engineering/communication from the University of Siegen, Siegen, Germany, in 1990.

In 1990, he joined the German Aerospace Center (DLR), Wessling, Germany, working in the development of a SAR raw data simulator. Then, he worked in software development for the X-SAR processor for the joint U.S.-Italian-German SIR-C/X-SAR Missions in 1994. When the data were in-house, he concentrated on the aspects of operational SAR processing of high data volumes. In 1995, he pioneered a completely automatic SAR processing system based on a robot-maintained mass memory archive. Before he became responsible for the development of the raw data analysis and screening system of SRTM, he developed a software for a phase-preserving ScanSAR processor for Radarsat-1. In the time between the Shuttle Radar Topography Mission and the start TerraSAR-X project, he left, for two years, the SAR domain and worked for the SCIAMACHY LIMB processor. Since 2002, he has been concerned with the TerraSAR-X radar system, and since the launch in 2007, he has been responsible for the TerraSAR-X SAR instrument operations. He is currently with the Microwaves and Radar Institute, DLR.

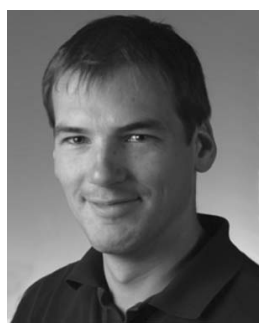

Daniel Schulze received the Diploma in aerospace technology from the University of Berlin, Berlin, Germany, in 2002.

In 2004, he joined the Microwaves and Radar Institute, German Aerospace Center (DLR), Wessling, Germany, working in the System Engineering and Calibration (SEC) segment of TerraSAR-X. In 2004 and 2005, he implemented the Instrument Command Generator and supervised the Long-Term Data Base implementation. Later on, he was a System Engineer for the Instrument Operations and Calibration Segment (IOCS), which are the operational systems of the SEC. During the test and integration phase, he coordinated the IOCS-internal and IOCS-ground segment tests. Since 2008, he has been a Project Manager of the joint TerraSAR-X and TanDEM-X SEC segment. 


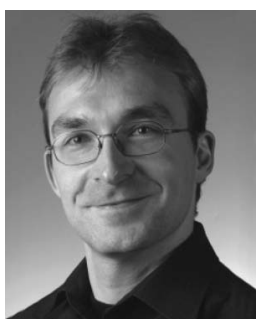

Johannes Böer received the Diploma in electrical engineering from the University of Karlsruhe, Karlsruhe, Germany, in 2004. During his studies, he was involved in the development of external calibration hardware (ground receiver/transponder) for the TerraSAR-X satellite.

Since 2004, he has been with the Microwaves and Radar Institute, German Aerospace Center (DLR), Wessling, Germany, working in the System Engineering and Calibration segment of TerraSAR-X and, later, TanDEM-X. He has supported the successful commissioning of the SAR instrument of TerraSAR-X and is responsible for the development and integration of subsystems used for instrument commanding, monitoring, maintenance, and calibration.

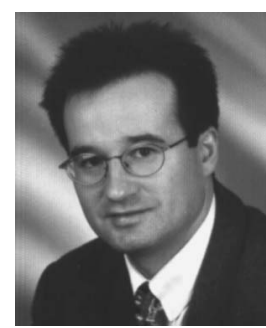

Josef Mittermayer (M'07) was born in Wartenberg, Oberbayern, Germany, in 1967. He received the Dipl.-Ing. (M.Sc.) degree in electrical engineering with a thesis on ScanSAR processing from the Technical University of Munich, Germany, in 1995, the Dr.-Ing. (Ph.D.) degree in the field of spotlight SAR processing from the University of Siegen, Germany, in 2000, and the M.Sc. degree in space system engineering from the Delft University of Technology, Delft, The Netherlands, in 2004.

From 1994 to 2001, he was with the Signal Processing Group of the Microwaves and Radar Institute, German Aerospace Center (DLR), Oberpfaffenhofen, Germany. Since 2002, he has been with the TerraSAR Project at DLR. From January 2004 until the end of the commissioning phase in 2008, he was the Group Leader and Project Manager of the System Engineering and Calibration, one of the three subprojects which form the TerraSAR-X Ground Segment. In addition, he was technically responsible for the TerraSAR-X commissioning phase. Since July 2008, he has been leading the SAR System Engineering Group of the Microwaves and Radar Institute, DLR.

Dr. Mittermayer, together with his colleagues, was the recipient of the IEEE Geoscience and Remote Sensing Society Transactions Prize Paper Award for a paper on air- and spaceborne stripmap and ScanSAR processing in 1996. He was the recipient of the DLR Science Award for his work on Spotlight-SAR processing in 2001. 